\title{
Article
}

\section{Analysis of wood decay and ligninolysis in Polyporales from the Nile Delta region of Egypt}

\author{
El-Gharabawy $\mathrm{HM}^{1,2}$, Detheridge $\mathrm{AP}^{2}$, El-Fallal $\mathrm{AA}^{1}$, El-Sayed $\mathrm{AKA}^{1}$, and \\ Griffith $\mathbf{G W}^{2 *}$
}

\begin{abstract}
${ }^{1}$ Botany and Microbiology Department, Faculty of Science, Damietta University, New Damietta, EGYPT.
${ }^{2}$ Institute of Biological, Environmental and Rural Sciences, Aberystwyth University, Adeilad Cledwyn, Penglais, Aberystwyth, Ceredigion SY23 3DD, WALES.
\end{abstract}

El-Gharabawy HM, Detheridge AP, El-Fallal AA, El-Sayed AKA, Griffith GW 2016 - Analysis of wood decay and ligninolysis in Polyporales from the Nile Delta region of Egypt. Mycosphere 7(4), 392-404, Doi 10.5943/mycosphere/7/4/1

\begin{abstract}
Wood decay fungi found on living or dead trees in fruit orchards in the Nile Delta region of Egypt were isolated into pure culture and their ligninolytic capabilities examined. Growth on ash sawdust was monitored by quantification of ergosterol and laccase/peroxidase activities using the model substrate ABTS. Two species from the polyporoid clade of order Polyporales exhibited faster growth and greater enzymatic activity than two isolates from the phlebioid clade but these differences were not reflected in dry weight loss of wood. Cellophane strips impregnated Remazol Brilliant Blue dye and $\mathrm{MnCl}_{2}$ impregnated plates were used to show the distinctive spatiotemporal patterns for the four species.
\end{abstract}

Key words - Class II peroxidases - dye decolourisation - tree pathogens - white rot fungi

\section{Introduction}

Lignin is the second most abundant biopolymer on earth comprising $\sim 30 \%$ of plant biomass (Boerjan et al. 2003). White rot fungi belonging to diverse orders within class Agaricomycetes of phylum Basidiomycota are the main organisms responsible for its catabolism (Floudas et al. 2012, Ohm et al. 2014) and the only organisms capable of degrading this complex heterogeneous polymer at a rate which approaches its rate of synthesis by plants. Catabolism of lignin is primarily mediated by various Class II haem-dependent peroxidases (PODs; EC 1.11.1.x) in Agaricomycetes. Also involved are laccases, believed to further oxidise the unstable products of peroxidase activity; and also glyoxal oxidases (GLOX; EC1.1.3.X) which synthesise the hydrogen peroxide required for peroxidase activity (Kersten \& Cullen 2014).

Mn-dependent PODs (MnP; EC 1.11.1.13) are the most widely distributed amongst the ligninolytic agaricomycetes and it is hypothesised that these were the ancestral PODs which evolved ca.300-400MYA (Floudas et al. 2012). More recently evolved ClassII PODs include the Lignin peroxidases (LiP; EC 1.11.1.14) and versatile peroxidases (VP; EC 1.11.1.16), which evolved within and are largely restricted to the orders Polyporales and Agaricales respectively (Ohm et al. 2014). Both these enzymes are able to oxidise higher redox potential substrates than $\mathrm{MnP}$ and do not require $\mathrm{Mn}$ as cofactor (hence they are known as MIP, Mn-independent peroxidase), utilising instead veratryl alcohol as a mediator (Ruiz-Duenas \& Martinez 2009). An 
unrelated group, the dye-decolourising peroxidases (DyP; EC 1.11.1.19) have also been recognised (Sugano 2009) and these are widely distributed amongst Eukaryotes and Bacteria. Although these are found in the genomes of many ligninolytic fungi, their contribution towards ligninolysis remains uncertain, although DyPs have been shown to oxidise lignin model compounds and to degrade wheat straw (Salvachua et al. 2013, Colpa et al. 2015).

Class Agaricomycetes also contains 'brown-rot' fungi which partially depolymerise rather than catabolise lignin. The mechanism of wood decay in these brown rot fungi involves the secretion of hydrogen peroxide into wood. In the presence of $\mathrm{Fe}^{3+}$ cations hydroxyl free radicals are formed via the Fenton reaction and these mediate the partial demethylation of lignin and removal of cellulose (Arantes et al. 2012). It has now been confirmed that brown rot fungi arose from white-rot ancestors and that their evolution also involved loss of POD-encoding genes. This strategy evolved independently within several orders of agaricomycetes (Agaricales; Boletales; Gloeophyllales; Polyporales) but there are several taxa where the mode of decay is inconsistent with established models of white and brown rot (Hibbett \& Donoghue 2001, Riley et al. 2014).

The majority of wood-decay fungi with strong ligninolytic ability are found within order Polyporales and it is apparent that a range of patterns of wood decay are found within this order, including the evolution of brown-rotting within one clade ('antrodia' clade) (Binder et al. 2013). More detailed biochemical and genomic analyses suggest that the balance of the different ligninolytic enzymes secreted by different members of the Polyporales can also vary. For instance Phanaerochaete chrysosporium has high peroxidase activity but no laccase activity, whilst Gelatoporia (=Ceriporiopsis) subvermispora undertakes selective delignification of wood and exhibits high laccase / MnP activity but possesses no LIP genes (Fernandez-Fueyo et al. 2012). Elucidation of how these patterns evolved has been hampered by the complex taxonomy of the Polyporales, a situation that has only recently begun to be clearly resolved with the aid of extensive multigene phylogenetic reconstructions and analysis of genome sequences (Binder et al. 2013, Floudas \& Hibbett 2015).

The impetus to study the process of ligninolysis by Fungi comes not only from the desire to better understand a process of central importance to terrestrial biogeochemical carbon cycling but also because effective delignification would greatly advance our ability to exploit lignocellulosic biomass for biofuel production (Shi et al. 2009). The highly oxidative and non-specific nature of these enzymatic systems also have potential for the removal of organic xenobiotic pollutants associated with industrial activity, for instance textile dyes and contaminated soils (Levin et al. 2005, Asgher et al. 2006). Furthermore, several members of order Polyporales are important tree pathogens and of agricultural importance (Smith 2012).

Our knowledge of the mechanisms of wood decay is largely based on the study of a limited number of well-characterised species, mostly in Polyporales. In this study four species of Polyporales originating from the Nile delta region of Egypt were subject to a detailed investigation of ligninolytic abilities.

\section{Materials \& Methods}

\section{Collection /isolation}

Basidiomycete samples were collected during a survey for wood-inhabiting fungi across the North-East Nile Delta region of Egypt represented by three governorates; Damietta, Dakahlia and Kafr El-Shaikh. The survey was carried out in a series of forays during autumn and winter seasons (September-March) of years 2013-14.

Isolation into pure culture was undertaken from basidiocarps or mycelial aggregations, directly after collection from the field sites according to the method of Stalpers (1978). Small pieces of either inner layers of basidiocarp tissue or collected fungal mycelia from trees and fruitbodies surface were excised on to plates of potato dextrose agar (PDA), 2\% malt extract agar (MA) and peptone dextrose malt agar under sterile conditions. Isolation plates were incubated at $28^{\circ} \mathrm{C}$ and axenic cultures were maintained on MA and PDA slopes at $4^{\circ} \mathrm{C}$ and also stored cryogenically 
in $10 \%$ glycerol at $-80^{\circ} \mathrm{C}$. Radial growth rate (RGR) was quantified for all isolates at $28^{\circ} \mathrm{C}$ on $3 \%$ MA in $90 \mathrm{~mm}$ Petri dishes inoculated with mycelial plugs of actively growing cultures.

\section{DNA barcoding}

Genomic DNA was extracted from isolated pure fungal cultures maintained on MA plates or from dried fruit bodies for non-isolated fungi using a CTAB-based method (Griffith \& Shaw 1998). PCR amplification of the part of the rRNA operon spanning the ITS2 spacer and LSUD1/D2 regions was undertaken with the primers ITS3 (5'- GCATCGATGAAGAACGCA -3') and HyglonR1 (5'-TAAAGCCATTATGCCAGCATCC-3'). PCR conditions were as follows: $2.5 \mathrm{mM}$ $\mathrm{MgCl}_{2}, 3 \mu \mathrm{M}$ BSA, $200 \mu \mathrm{M}$ dNTPs mixture, $0.25 \mu \mathrm{M}$ of each primer, $1 \mathrm{U}$ Taq DNA polymerase (Promega) and $2 \mu \mathrm{l}$ (1-10 ng) genomic DNA in GoTaq Flexi buffer. The thermal cycling protocol was: initial denaturation $\left(96^{\circ} \mathrm{C} / 5 \mathrm{~min}\right)$ followed by 45 amplification cycles $\left(95^{\circ} \mathrm{C} / 30 \mathrm{sec}, 53^{\circ} \mathrm{C} / 30\right.$ sec, $72^{\circ} \mathrm{C} 45 \mathrm{sec}$ ) and final extension $72^{\circ} \mathrm{C} / 45 \mathrm{sec}$ ).

PCR-DNA products were purified using spin column PCR purification kit (NBS Biologicals Ltd., Huntingdon, UK) as directed by the attached manual and stored at $-20^{\circ} \mathrm{C}$. PCR products were visualized by gel electrophoresis system (1.5\% agarose gel in 1x TBE buffer, stained with SYBR safe (Invitrogen Ltd.). DNA sequencing was conducted using Sanger BigDye technology at the IBERS Sequencing Facility (Aberystwyth) using forward and reverse PCR primers. DNA sequences were edited and analyzed using the Geneious R6 software (Drummond et al. 2011).

\section{Ash sawdust cultures}

Growth of cultures on Fraxinus excelsior (European ash) sawdust was conducted in order to assess the production of ligninolytic enzyme and wood decay rates during an eight week incubation period at $25^{\circ} \mathrm{C}$. Ashwood (heartwood, supplied by Rex Nusum, Abergwyngregyn, Wales) was milled to $1 \mathrm{~mm}$ mean particle size, and sterilised by autoclaving twice $\left(115^{\circ} \mathrm{C} / 15 \mathrm{~min}\right)$ in $4 \mathrm{~g}$ aliquots. The aliquots were aseptically transferred to $90 \mathrm{~mm}$ Petri dishes (Fisher; single vent) and mixed with $10 \mathrm{ml}$ sterile distilled water, giving a moisture content of $71 \%(\mathrm{w} / \mathrm{w})$. The centre of the wetted sawdust was inoculated with a single $10 \mathrm{~mm}$ mycelial plug from an actively growing culture (four replicate cultures per isolate plus one set of control [uninoculated] plates). At weekly intervals for eight weeks, a one-eighth segment of the colonised sawdust (0.5 g d.w.; $1.75 \mathrm{~g}$ f.w.) was excised aseptically for analysis.

\section{pH measurement}

The colonised sawdust was mixed well and $350 \mathrm{mg}$ taken for ergosterol analysis (see below). The remainder was mixed with $6 \mathrm{ml}$ distilled water and incubated on an orbital shaker (150 $\mathrm{rpm}$ ) for $15 \mathrm{~min}$ at $4^{\circ} \mathrm{C}$. After allowing the sawdust to settle, $\mathrm{pH}$ was measured with $\mathrm{HACH} \mathrm{pH}$ meter (H 170. USA). Following $\mathrm{pH}$ measurements, $2 \mathrm{ml}$ buffer $(250 \mathrm{mM}$ Sodium acetate buffer, PH 5.5, $0.5 \mathrm{~g} / \mathrm{l}$ Tween 80 ) was added to these samples and they were incubated at $4^{\circ} \mathrm{C}$ on the orbital shaker $(150 \mathrm{rpm})$ for a further $16 \mathrm{hrs}$.

\section{Ligninolytic enzyme assays}

Following overnight incubation, tubes were left to settle and $2 \mathrm{ml}$ supernatant removed for enzyme assays. Four linked assays were conducted using ABTS (2,2' 'azino-bis [3ethylbenzthiazoline-6-sulphonic acid]) $(500 \mu \mathrm{M})$ as a model substrate for laccases and peroxidases, at two different $\mathrm{pH}$ values (3.5 and 4.5). Assays were conducted in 96 well microplates using a Biotek Elx808 plate reader. The assay volume was $200 \mu \mathrm{l}$ buffered with either $50 \mathrm{mM}$ sodium tartrate $(\mathrm{pH} 3.5)$ or $50 \mathrm{mM}$ sodium malonate $(\mathrm{pH} 4.5)$. For laccase assays, catalase (2 $\mathrm{U}$ bovine catalase, Sigma) was added to remove any peroxide present. For peroxidase assays, $100 \mu \mathrm{M} \mathrm{H}_{2} \mathrm{O}_{2}$ and $300 \mu \mathrm{M} \mathrm{MnCl}{ }_{2}$ was added to the $\mathrm{pH} 4.5$ assay (to quantify Mn-dependent peroxidase [MnP] activity), whilst for the pH3.5 assays $100 \mu \mathrm{M} \mathrm{H}_{2} \mathrm{O}_{2}$ and $300 \mu \mathrm{M}$ EDTA (to chelate any endogenous $\mathrm{Mn}$ ) was added (to quantify Mn-independent peroxidase [MIP] activity). Peroxidase activity was calculated by subtracting the corresponding laccase activity at that $\mathrm{pH}$ value. 
Assay plates were incubated at $30^{\circ} \mathrm{C}$ in the plate reader, and ABTS oxidation was monitored by the increase in absorbance at $405 \mathrm{~nm}\left(\epsilon 405=36000 \mathrm{M}^{-1} \mathrm{~cm}^{-1} ; 0.75 \mathrm{~cm}\right.$ absorbance path length) over a $5 \mathrm{~min}$ period. One Unit of activity defined here as the amount of enzyme that catalyses the formation of $1 \mu \mathrm{mol}$ of oxidized ABTS product per minute. For each biological replicate (four per species) three assay replicates were conducted. Enzymes activity was calculated as Unit per $\mathrm{Kg}$ wood (Unit is the amount of enzyme that catalyses the formation of $1 \mu \mathrm{mol}$ of product per minute, and the absorbance path length was $0.75 \mathrm{~cm}$ ).

\section{Dry weight loss}

Following enzyme extraction, the sawdust was freeze-dried and weighted to calculate loss of dry weight relative to the original sawdust.

\section{Analysis of ergosterol}

Growth of fungi in ashwood cultures was measured via quantification of the fungus-specific sterol ergosterol. Colonised sawdust $(350 \mathrm{mg})$ was oven-dried $\left(60^{\circ} \mathrm{C} / 16 \mathrm{hr}\right)$, mixed with $3 \mathrm{ml} 10 \%$ (w/v) $\mathrm{KOH}$ in methanol and incubated at $80^{\circ} \mathrm{C}$ for $30 \mathrm{~min}$, according to the method of (Manter et al. 2001). Samples were then partitioned with $2 \mathrm{ml}$ petroleum ether $\left(40-60^{\circ} \mathrm{C}\right.$ bp) three times and the extracted sterols were dissolved in $1 \mathrm{ml}$ methanol (HPLC grade). 7-Dehydrocholesterol (7DHC) was used as internal standard.

The identification and quantification of ergosterol were carried out by High Performance Liquid Chromatography using HPLC-LDC Analytical system with a constaMetric 3200 pump and a UV-100 detector Spectro Monitor 3200 (Altech). Samples were injected via $200 \mu 1$ loop injection and separated using Spherisorb® ODS2 silica-based C18 HPLC columns (5 $\mu$ M particle size). Methanol was used as a mobile phase with a flow rate of $1.5 \mathrm{ml} / \mathrm{min}$, and retention times were between 9-10 min. Serial dilutions of ergosterol stock $(0-100 \mu \mathrm{g} / \mathrm{ml})$ prepared in HPLC methanol were used as standard calibration plot.

Ergosterol content of samples was derived from HPLC chromatographs by comparison of peak values ( $282 \mathrm{~nm}$; 9 min retention time) against values for a standard curve. The efficiency of extraction was calculated using the relative peak area of the 7-DHC standard which was used for correction of ergosterol values. Concentrations of ergosterol were converted to mycelial dry mass using the value $5.5 \mathrm{mg}$ ergosterol per gram mycelial dry mass (Gessner \& Chauvet 1993).

\section{Dyed cellophane strips and Manganese oxidation plates}

The dye decolourisation capabilities of the four isolates were tested on stained cellophane strips impregnated with the anthraquinone dye Remazol Brilliant Blue R (Sigma-Aldrich, UK; R8001; =Reactive Blue 19; $\mathrm{C}_{22} \mathrm{H}_{16} \mathrm{~N}_{2} \mathrm{Na}_{2} \mathrm{O}_{11} \mathrm{~S}_{3}$ ), as described by Hedger (1982) and Detheridge (2010). Autoclaved stained strips $\left(25 \mathrm{~cm}^{2}\right)$ were laid flat on the surface of $1.5 \%$ distilled water agar in $90 \mathrm{~mm}$ Petri dishes. Strips were then inoculated centrally with $7 \mathrm{~mm}$ actively growing mycelial plugs and incubated at $25^{\circ} \mathrm{C}$ ( 3 replicates per isolate). Cultures were then photographed weekly on a light box.

Petri dishes containing 2\% MA, supplemented with $0.5 \mu \mathrm{M} \mathrm{MnCl}_{2}$ as described by Steffen et al. (2002), were inoculated centrally with $10 \mathrm{~mm}$ mycelial plugs (four replicates), and incubated at $25^{\circ} \mathrm{C}$. Plates were monitored weekly for the production of pigmentation in the medium (due to $\mathrm{MnO}_{2}$ formation) over a four week period. For each isolate, comparison was made to cultures growing on Mn-free MA plates.

\section{Results}

\section{Sample collection, isolation and identification}

The four isolates studied here were collected from live or dead trees in fruit orchards across the Nile Delta region of Egypt (Table 1). Isolation into pure culture from basidiocarp context tissues was also undertaken from fresh material. Morphological analysis of freshly-collected 
basidiocarps was undertaken and initial identifications were confirmed by DNA barcoding of pure culture isolates. Each sample belongs to a different family within order Polyporales (Table 1).

Table 1 List of origin and identity of the four isolates (RGR indicates radial growth rate on $2 \%$ MA; Clade* indicates to which of the Larsson et al. (2004) clades each isolate belongs).

\begin{tabular}{|c|c|c|c|c|c|c|c|}
\hline Species & Family (Clade*) & $\begin{array}{l}\text { Isolate } \\
\text { code }\end{array}$ & $\begin{array}{r}\text { GenBank } \\
\text { Accession }\end{array}$ & $\begin{array}{c}\text { RGR } \\
(\mathrm{mm} / \mathrm{d})\end{array}$ & Host tree & $\begin{array}{l}\text { Collection } \\
\text { Date }\end{array}$ & Area (Lat/Long) \\
\hline $\begin{array}{c}\text { Oxyporus (="Emmia") } \\
\text { latemarginatus }\end{array}$ & $\begin{array}{l}\text { Irpicaceae } \\
\text { "phlebioid" }\end{array}$ & EM26 & KX428467 & 13.0 & Mangifera indica (Cut stump) & 18-Dec-13 & $\begin{array}{l}\text { Damietta; El-Senaniah } \\
\text { (N 31.2611, E 31.4648) }\end{array}$ \\
\hline Ganoderma resinaceum & $\begin{array}{l}\text { Ganodermataceae } \\
\text { "polyporoid" }\end{array}$ & GR33 & KX428468 & 8.7 & Casuarina equisetifolia (Live) & 1-Jan-14 & $\begin{array}{l}\text { Dakahlia; Mansoura Univ. } \\
\text { (N 31.0403, E 31.3590) }\end{array}$ \\
\hline Megasporoporia minor & $\begin{array}{l}\text { Polyporaceae } \\
\text { "polyporoid" }\end{array}$ & MG65 & KX428469 & 10.4 & Salix alba (Live) & 4-Mar-14 & $\begin{array}{l}\text { Dakahlia; Dekernis } \\
\text { (N 31.0637, E 31.6577) }\end{array}$ \\
\hline Phanerochaetaceae sp. & $\begin{array}{l}\text { "Byssomerulius" clade } \\
\text { "phlebioid" }\end{array}$ & UN63 & KX428470 & 1.6 & Phoenix dactylifera (Dead) & 26-Feb-14 & $\begin{array}{l}\text { Kafr El-Shaikh; Baltim } \\
\text { (N 31.5764, E 31.0796) }\end{array}$ \\
\hline
\end{tabular}

\section{Growth rate on agar media and in ash sawdust culture}

The four isolates showed a 20 -fold variation in radial growth rate (RGR) when grown on $2 \%$ MA plates (Table 1). However, when inoculated onto ash sawdust, there was only a three-fold difference in biomass accumulation as assessed by quantification of ergosterol (Fig. 1). The rank order of growth rate was similar on both MA and ash sawdust, though isolate grew relatively more slowly and isolate UN63 more quickly. The fact that growth of MG65 on ash did not increase from weeks 6 to 8, whereas biomass of UN63 doubled during the same period suggests that the latter isolate is able to access the more recalcitrant nutrients in wood despite its slow growth on a medium rich in soluble sugars.

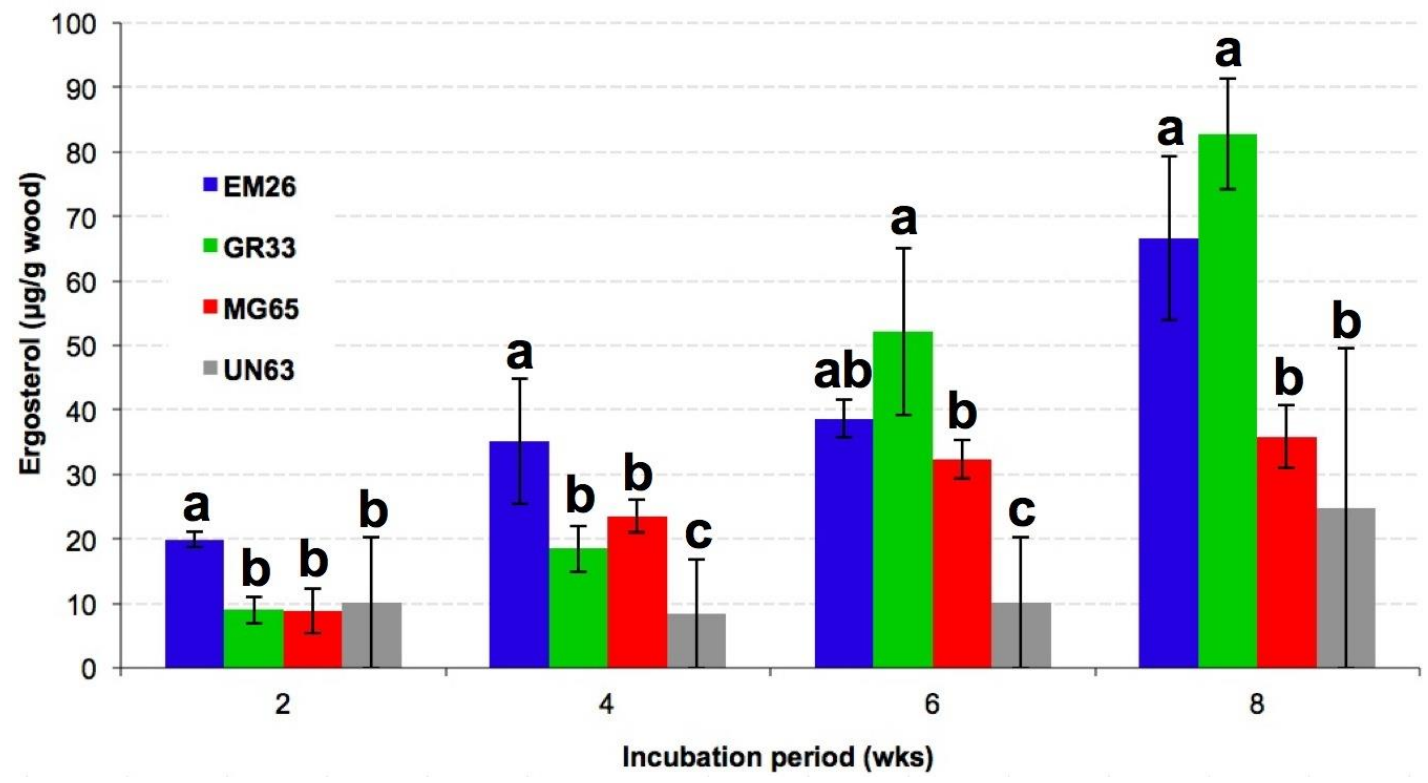

Fig. 1 - Ergosterol content ( $\mu$ g ergosterol/ g dry wt. wood) of ash sawdust cultures during the 8 week incubation period. Error bars indicate SD; $n=4$. For each timepoint, ergosterol levels that are significantly different (Tukey's test) are indicated by different superscript letters.

\section{Substrate dry weight loss and pH decline in ash sawdust culture}

Mean dry weight loss at four weeks was greatest for isolate EM26 (Fig. 2), consistent with its more biomass accumulation on ash wood (Fig. 1). However, by eight weeks there was no correlation between biomass accumulation and dry weight loss with the greatest dry weight loss (20\%) observed for isolate MG65 (Fig. 2). Proliferation of fungal mycelium and catabolism of wood was accompanied by a drop in $\mathrm{pH}$ from ca. 5.7 (uninoculated sawdust) to $4.6( \pm-0.2)$, with the rate of acidification being slowest for the slow-growing UN63 (Fig. 3). 


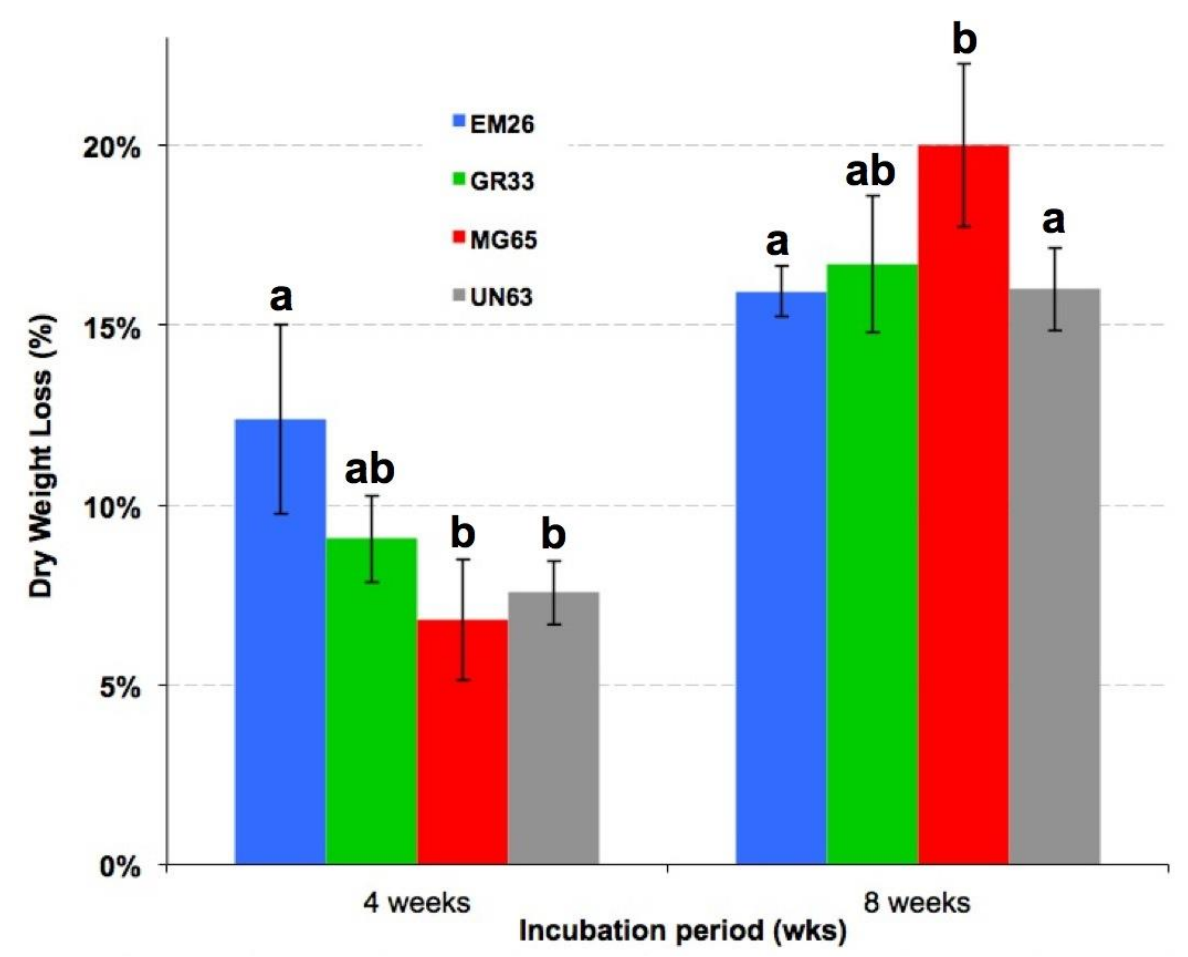

Fig. 2 - Weight loss of ash wood as a result of decay by different species over 8 weeks of incubation periods. Error bars indicate SD; $=4$. For each timepoint, dry weight loss values that are significantly different (Tukey's test) are indicated by different superscript letters.

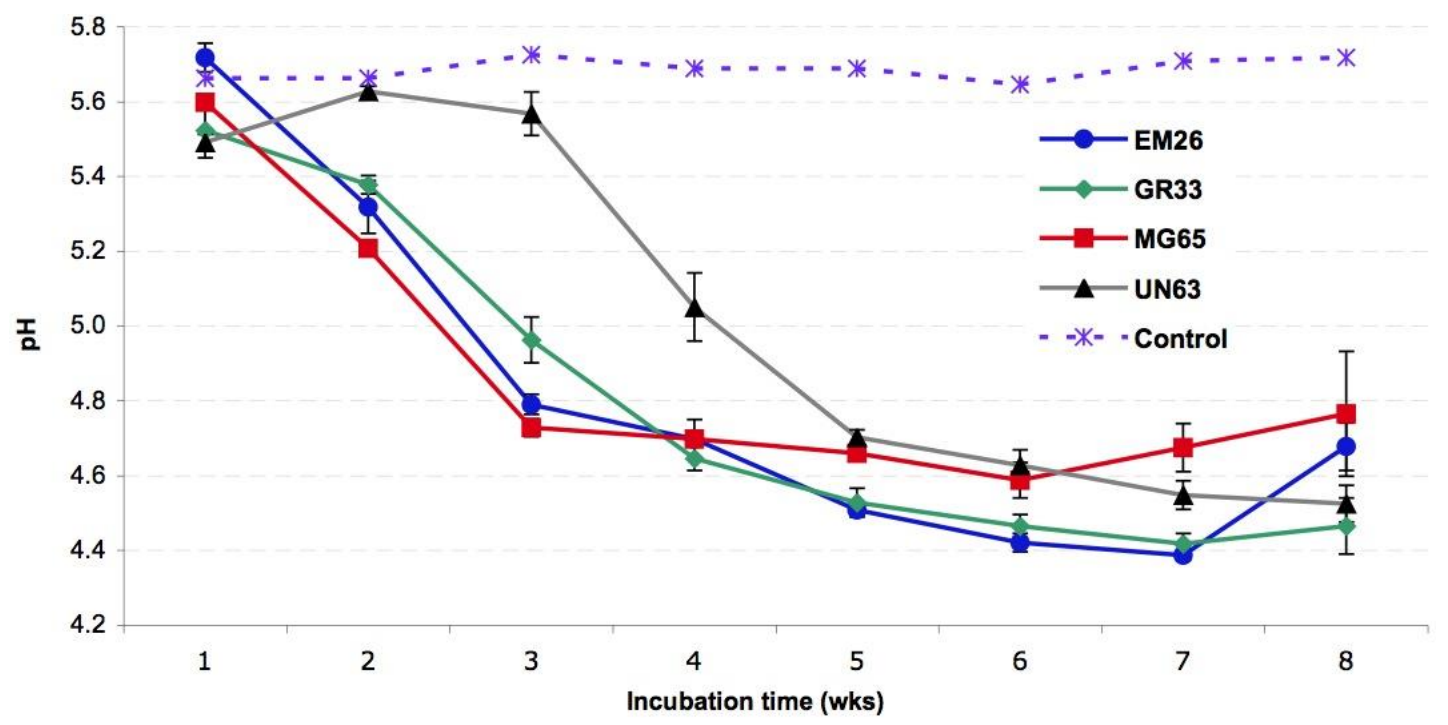

Fig. 3 - Change in ashwood pH during the 8 week incubation. Error bars indicate SD; $n=4$. $\mathrm{pH}$ of control uninoculated ash sawdust is shown as dotted line.

\section{Enzyme production on ashwood}

The activity of ligninolytic enzymes of cultures growing on ahs sawdust was monitored over the eight weeks of incubation period. A microtitre plate assay using the model substrate ABTS was developed to quantify four different enzymatic activities. The primary aim of these assays was to quantify the activities of $\mathrm{MnP}$ (manganese-dependent peroxidase) and (MIP) Mn-independent peroxidases which have different $\mathrm{pH}$ optima (3.5 and 4.5 respectively). Laccase can also oxidise ABTS in the absence of $\mathrm{H}_{2} \mathrm{O}_{2}$, so it was necessary to assay activity of this enzyme at both $\mathrm{pH}$ values, subtracting laccase activity from the total ABTS oxidation in the presence of $\mathrm{H}_{2} \mathrm{O}_{2}$ in order to quantify MnP/MIP activity. 

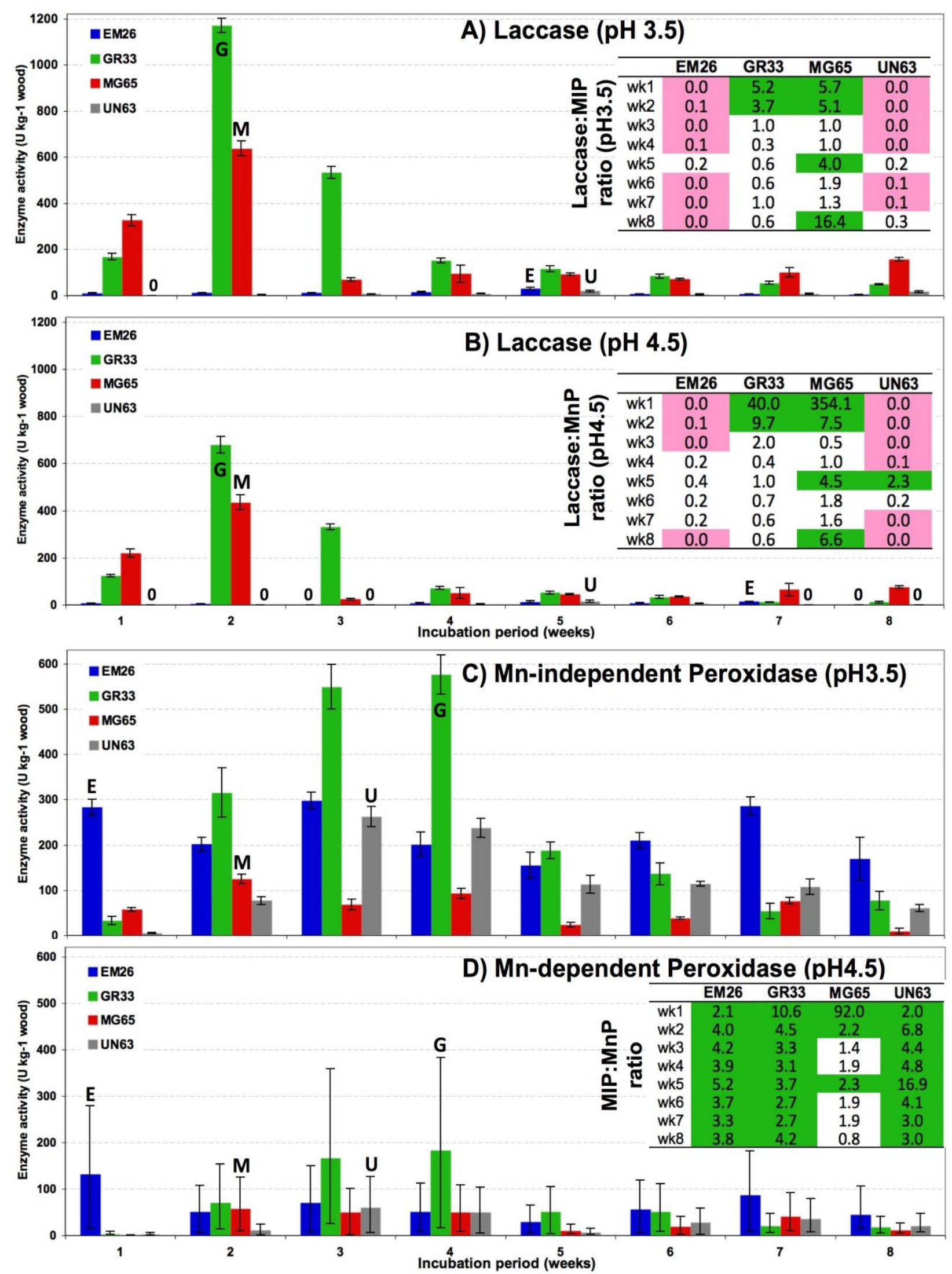

Fig. 4 - Change in lignolytic enzyme activity during the 8 week incubation (Bars indicate SD; $\mathrm{n}=4$ ). Letter on peaks indicate the highest mean activity of particular enzymes for each isolate (E=EM26; G=GR33; M=MG65; U=UN63). Zero enzyme activities are indicated by '0'. Inset tables show ratios of Laccase:MIP (pH3.5), Laccase:MnP (pH4.5) and MIP:MnP with indicating high $(\geq 5$; green $)$ and low $(\leq 0.1$; pink) ratios. 
Overall, isolate GR33 produced the greatest levels of activity of all four enzymes (Fig. 4), with laccase activity peaking at two weeks and MIP/MnP activity at 3/4 weeks. Isolate MG65 showed a similar temporal pattern of ligninolytic enzyme production but the ratio of laccase:peroxidase activity (Fig. 4 A,B inset table) was much greater, with the ratio of MIP:MnP activity (Fig. 4. D inset table) being significantly lower than for the other isolates. In contrast to GR33 and MG65, EM26 and UN63 showed only very low levels of laccase activity and MIP activity being much greater (ca. 4-fold) than MnP activity across the incubation period. The low levels of laccase activity in these isolates peaked later (5-7 weeks), with MIP/MnP activity peaking at 1 or 3 weeks (EM26 and UN63 respectively) but showing a much lesser temporal variation in activity compared to GR33 and MG65.

\section{Dye decolourisation and manganese oxidation}

Remazol BBR is an anthroquinone dye whose decolourisation mimics the oxidation of lignin. Impregnation of the dye into cellophane strips allows not only the oxidation of the dye to be monitored over several weeks (Fig. 5) but also the spatial patterns of dye oxidation to be observed. In all cases the mycelium had colonised the whole dish within 4 weeks, except that UN63 failed to do so by 2 weeks. The most rapid and even dye decolourisation was mediated by EM26 consistent with its high RGR on MA (Table 1) and high MIP activity during the initial stages of growth on ash sawdust (Fig. 4C). In contrast, GR33 caused a much lower amount of decolourisation and this was localised near the inoculum plug and in patches towards the edge of the strips. MG65 also exhibited some patchiness in the patterns of dye oxidation but still at a high level of overall decolourisation. UN63, with a much lower RGR on MA than the other cultures achieved only limited dye decolourisation after 2 weeks. However, decolourisation not even across colony, within concentric rings of dye removal around the inoculum plug.

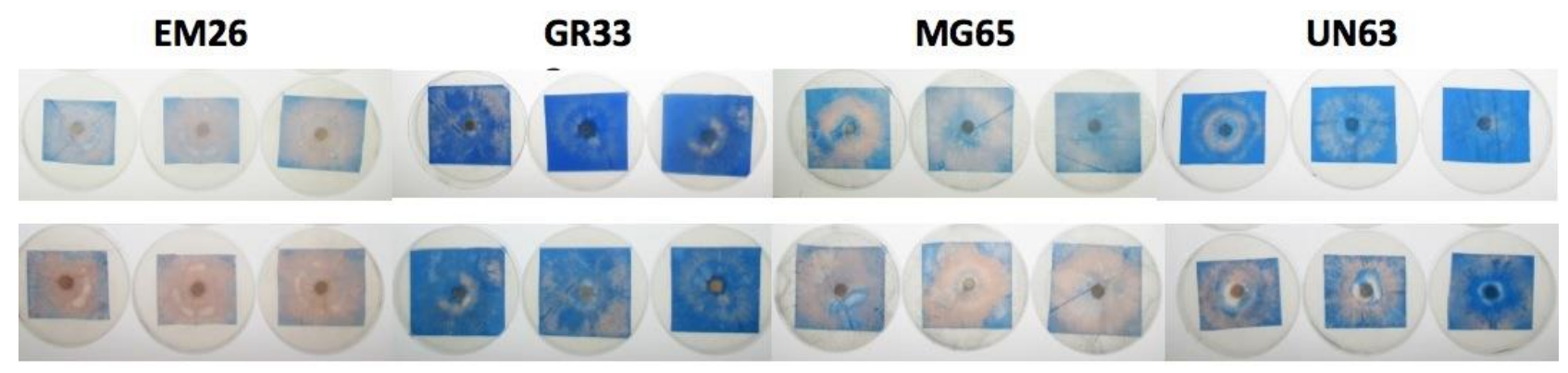

Fig. 5 - Decolourisation of cellophane strips dyed with Remazol Brilliant Blue dye (azo dye; three replicate strips per isolate) after two (upper row) or four (lower row) weeks of incubation at $25^{\circ} \mathrm{C}$.

The addition of $\mathrm{Mn}_{2} \mathrm{SO}_{4}$ to agar media allows the oxidation of $\mathrm{Mn}^{2+}$ to insoluble $\mathrm{MnO}_{2}$ by POD enzymes to be observed as the formation of dark brown precipitates in the agar (Fig. 6). A highly localised pattern of precipitation was observed for EM26, discrete clumps at the edge of the colony oxidative within 2 weeks, consistent with the high MIP/MnP activity observed in ash sawdust cultures after 1/2 weeks. MG65 was the only other isolate which formed visible precipitate by 2 weeks but this was in the form of very fine particles of $\mathrm{Mn}_{2} \mathrm{O}_{3} / \mathrm{MnO}_{2}$ distributed evenly across the underside of the colony. GR33 formed dark heterogeneous patches of $\mathrm{Mn}_{2} \mathrm{O}_{3} / \mathrm{MnO}_{2}$ but these emerged quite suddenly between 2 and 4 weeks, consistent with the peak of MIP/MnP activity in ashwood cultures at 3/4 weeks and also the very patchy nature of dye decolourisation. UN63 showed the lowest amount of Mn oxidation with only a slight darkening of the medium after 4 weeks, coincident with peak activity of MIP/MnP at 3-4 weeks in ashwood culture.

\section{Discussion}

In this study, the ligninolytic abilities of four white rot fungi, belonging to order Polyporales was investigated. The four species belonged to different families within Polyporales 
(Table 1), two (G. resinaceum [GR33]; M. minor [MG65]) in the 'core polyporoid' clade and two ('Emmia' laermarginata [EM26]; Phanerochaetaceae sp. [UN63]) in 'phlebioid'clade, as defined by Larsson et al. (2004). These are the two main groups of white rot fungi within this large order, whose natural grouping has long been a matter of taxonomic uncertainty. However, recent phlyogenomic and multigene analyses (Binder et al. 2013, Floudas \& Hibbett 2015) have been able to establish a stable phylogenetic backbone.

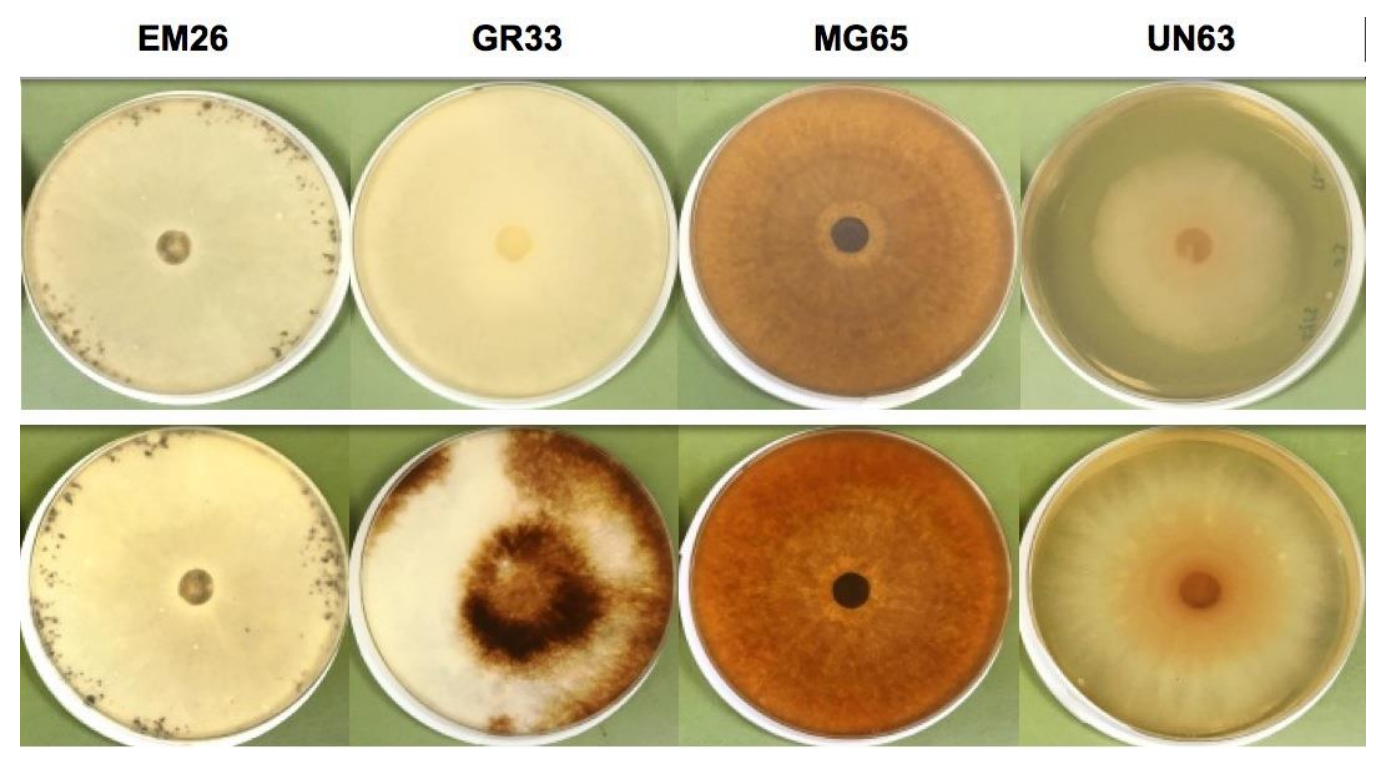

Fig. $6-\mathrm{MnCl}_{2}$ impregnated MA plates inoculated with the four fungi and incubated for two (upper row) or four (lower row) weeks at $25^{\circ} \mathrm{C}$. Dark zones / spots indicate areas of deposition of $\mathrm{MnO}_{2}$.

One result of past uncertainties is that many of the current genera are polyphyletic and many familial affiliations are uncertain. This has led to taxonomic and nomenclatural confusion, even when DNA barcodes are available. Therefore the affinities of some of the species require further explanation. EM26 has recently been reclassified as 'Emmia' (formerly Oxyporus) latermarginata (Zmitrovich \& Malysheva 2014) in recognition of the fact that the genus Oxyporus is polyphyletic, with $O$. latermarginata ,being closely related to Irpex spp. (family Irpicaceae) in Polyporales, whereas the other members of this genus are in order Hymenochaetales. However, the new generic name Emmia (Zmitrovich \& Malysheva 2014) has yet to be validly described (see indexfungorum.org), hence we have used inverted commas ('Emmia'). A single isolate (UN63), could not be definitively identified via microscopy or DNA barcoding but was morphologically and phylogenetically close to Meruliopsis within the 'Byssomerulius' subclade (sensu Floudas et al., 2015) of the phlebioid clade of Polyporales. This species will be more fully described separately.

In terms of dry weight loss of substrate and enzyme production, G. resinaceum and $M$. minor (both polyporoid clade) were the most potent wood decayers. Both caused acidification of the ashwood during incubation, a general observation during fungal wood decay (Jellison et al. 1997, Ostrofsky et al. 1997) due to secretion of the oxalic or glyoxylic acids required for the function of MnP (Urzua et al. 1998). In the present study pH stabilised at ca. 4.6 close to the accepted optimum for MnP activity (Boer et al. 2006).

$G$. resinaceum and $M$. minor differed in the relative amounts of laccases and peroxidase activity secreted. G. resinaceum secreted higher enzyme titres, possibly related to its more rapid growth on wood (Fig. 1), but $M$. minor caused more dry weight loss of substrate and also secreted more MIP relative to MnP. Genome sequence analysis of three members of the core polyporoid clade (Ruiz-Duenas et al. 2013) found that these all contained 14-30 peroxidase genes but that they differed significantly by the type of peroxidase present. For instance Ganoderma sp. (G. lucidum complex) contained no LIP genes but two VP genes, as well as several DYP genes. The presence of a similar spectrum of peroxidases in $G$. resinaceum is consistent with the observed patterns of 
enzyme activity. The temporal pattern of enzyme activity differed between $G$. resinaceum and $M$. minor and this was apparent in the more rapid Mn oxidation and dye decolourisation observed for the latter (Figs. 5/6). Despite its slower growth on wood (Fig. 1) however, M. minor caused greater dry weight loss over the eight week period.

The two isolates studied from the phlebioid clade showed rather different growth patterns to each other, ' $E$ '. latemarginata growing quickly on both agar and ash sawdust in contrast to Phaerochaetaceae sp. UN63. However, both caused similar levels of substrate dry weight loss on wood and both secreted only very low levels of laccase. In both cases the ratio of MIP:MnP activity was consistently high (4-7:1) but no distinct peaks of activity as seen with G. resinaceum and $M$. minor were observed. Genome analysis of several other members of the phlebioid clade (RuizDuenas et al. 2013) found a similar number of peroxidase genes and as with the polyporoid clade a diversity between the three genomes in terms of MnP vs MIP (LIP/VP/DYP) enzymes.

It is noteworthy that many (but not all) wood decay fungi possess several DYP genes and that in several species, including Bjerkandera adusta and Irpex lacteus (closely related to E. latermarginata) the enzymes associated with these genes have been shown to be secreted and to be capable of oxidation of anthroquinone dyes (Salvachua et al. 2013, Linde et al. 2015, Yoshida \& Sugano 2015). Salvachua et al. (2013) also showed that addition of the purified I. lacteus DYP could accelerate degradation of wheat straw, hitherto the only direct evidence that these enzymes contribute to lignocellulose decay.

The advent of genome sequencing has challenged the orthodoxies of wood-decay, not only with the potential role of DYPs being recognised but also that a huge diversity of enzymatic and non-enzymatic wood decay mechanisms exist (Riley et al. 2014, Floudas et al. 2015). The polyphyletic origins of brown rot decay are attributed to increased energetic efficiency. Modification rather than catabolism of lignin allows the associated cellulose to be accessed more rapidly and at lower cost (both energetically and in terms of investment of nutrients in extracellular enzymes) (Arantes et al. 2012). However, the fact that only a minority of wood decay fungi form brown rots suggests that this non-enzymatic strategy is only effective in a limited range of scenarios.

Recent genome sequencing activities have examined several species which do not conform to typical white or brown rot decay strategy (Riley et al. 2014) and which possibly indicating transitional stages. These detailed studies have been conducted on members of order Agaricales, but within Polyporales there are several species outside the main 'antrodia' (brown rot) clade which are reported to cause brown rot decay.

These include Ceriporia reticulata, Leptoporus mollis and Meruliopsis albostramineus (Lombard \& Gilbertson 1965, Gilbertson 1981, Lindner \& Banik 2008), which all lie within 'Byssomerulius' subclade of the phlebioid clade (Floudas \& Hibbett 2015) and require further investigation. Phanerochaetaceae sp. UN63, also within the 'Byssomerulius' clade sensu (Floudas \& Hibbett) is closely related to these taxa. The evidence presented here suggests that it does secrete both PODs and laccases albeit at a low level. However, it caused loss of substrate dry weight in ash sawdust culture comparable to the other isolates which not only grew more rapidly (on wood and agar) but also secreted much higher enzyme titres. This suggests that it may have an unusual mechanism of wood decay.

Given the industrial focus of most studies of ligninolytic enzymes, there is relatively little consideration given to how the enzymology of ligninolysis links to the ecological aspects of wood decay. Two of the fungi studied here (GR33 and MG65, both core polyporoid clade) were found growing and fruiting on living wood, with G. resinaceum, often reported as a weak pathogen (buttrot) of Casuarina and other trees in the subtropics (Rajchenberg \& Robledo 2013). Whilst it might be expected that fungi which colonise living rather than dead wood have altered patterns of expression of ligninolytic enzymes, the matter of whether a given species is able to colonise living wood is rather unclear (Schwarze \& Ferner 2003).

Furthermore, many Polyporales are latent invaders (e.g. including several Phlebia, Phaneorchaete spp.), colonising living tissue but remaining quiescent until the host tissue dies 
(Chapela \& Boddy 1988, Boddy 2001). However, it may be the case that primary invaders (including pathogens and latent invaders) would share certain patterns of colonisation/resource explotiation, for instance initial rapid growth followed by delayed explotation wherein the ligninolytic enzymes are deployed. In the enzyme assays, both $G$. resinaceum and $M$. minor showed similar patterns of lacasse activity, but the delayed release of peroxidases was stronger in the former, which also had the highest biomass.

The environmental conditions that pertain in wood being colonised and decayed by fungi are difficult to mimic in vitro, even when using ash sawdust. However, the data presented here from both enzyme assays (Fig. 3) and plate assays (Figs. 4/5) suggest a clear spatiotemporal dimension to ligninolytic activity which is distinct for all four of the species examined here. Our novel deployment of the dye-stained cellophane strips, combined with the use of Mn-supplemented media, provide a method whereby such patterns can be rapidly screened. The bleaching of organic dyes dissolved in agar media was used by Jarosz-Wilkolazka et al. (2002) to screen for ligninolytic fungi, and more recently Barrasa et al. (2014) to differentiate spatial patterns of enzyme secretion by humus- and wood-inhabiting fungi. Here we show that impregnation of dyes into cellophane strips can enhance the spatiotemporal resolution with which these patterns can be visualised.

\section{Acknowledgements}

The authors wish to the Egyptian Government for a grant to allow HME to undertake research at Aberystwyth University and also to Damietta University for funding of this work.

\section{References}

Arantes V, Jellison J, Goodell B. 2012 - Peculiarities of brown-rot fungi and biochemical Fenton reaction with regard to their potential as a model for bioprocessing biomass. Applied Microbiology and Biotechnology 94(2), 323-338.

Asgher M, Shah S, Ali M, Legge R. 2006 - Decolorization of some reactive textile dyes by white rot fungi isolated in Pakistan. World Journal of Microbiology and Biotechnology 22(1), 8993.

Barrasa J, Blanco MN, Esteve-Raventos F, Altes A, Checa J, Martinez AT, Ruiz-Duenas FJ. 2014 - Wood and humus decay strategies by white-rot basidiomycetes correlate with two different dye decolorization and enzyme secretion patterns on agar plates. Fungal Genetics and Biology 72, 106-114.

Binder M, Justo A, Riley R, Salamov A, Lopez-Giraldez F, Sjökvist E, Copeland A, Foster B, Sun H, Larsson E. 2013 - Phylogenetic and phylogenomic overview of the Polyporales. Mycologia 105(6), 1350-1373.

Boddy L. 2001 - Fungal community ecology and wood decomposition processes in angiosperms: from standing tree to complete decay of coarse woody debris. Ecological Bulletins 49, 4356.

Boer CG, Obici L, De Souza CGM, Peralta RM. 2006 - Purification and some properties of Mn peroxidase from Lentinula edodes. Process Biochemistry 41(5), 1203-1207.

Boerjan W, Ralph J, Baucher M. 2003 - Lignin biosynthesis. Annual Reviews of Plant Biology 54(1), 519-546.

Chapela IH, Boddy L. 1988 - The fate of early fungal colonizers in beech branches decomposing on the forest floor. FEMS Microbiology Ecology 4(5), 273-283.

Colpa DI, Fraaije MW, van Bloois E. 2015 - DyP-type peroxidases: a promising and versatile class of enzymes. Journal of Industrial Microbiology \& Biotechnology 41(1), 1-7.

Detheridge A, 2010. The evolution of wood decay in basidiomycete Fungi, PhD thesis, Aberystwyth University.

Drummond A, Ashton B, Buxton S, Cheung M, Cooper A, Duran C, Field M, Heled J, Kearse M, Markowitz S, Moir R, Stones-Havas S, Sturrock S, Thierer T, A W. 2011 - Geneious v5.4. Available from: http://www.geneious.com/. 
Fernandez-Fueyo E, Ruiz-Duenas FJ, Ferreira P, Floudas D, Hibbett DS, Canessa P, Larrondo LF, James TY, Seelenfreund D, Lobos S. 2012 - Comparative genomics of Ceriporiopsis subvermispora and Phanerochaete chrysosporium provide insight into selective ligninolysis. Proceedings of the National Academy of Sciences 109(14), 5458-5463.

Floudas D, Binder M, Riley R, Barry K, Blanchette RA, Henrissat B, Martinez AT, Otillar R, Spatafora JW, Yadav JS. 2012 - The Paleozoic origin of enzymatic lignin decomposition reconstructed from 31 fungal genomes. Science 336(6089), 1715-1719.

Floudas D, Held BW, Riley R, Nagy LG, Koehler G, Ransdell AS, Younus H, Chow J, Chiniquy J, Lipzen A. 2015 - Evolution of novel wood decay mechanisms in Agaricales revealed by the genome sequences of Fistulina hepatica and Cylindrobasidium torrendii. Fungal Genetics and Biology 76, 78-92.

Floudas D, Hibbett DS. 2015 - Revisiting the taxonomy of Phanerochaete (Polyporales, Basidiomycota) using a four gene dataset and extensive ITS sampling. Fungal Biology 119(8), 679-719.

Gessner MO, Chauvet E. 1993 - Ergosterol-to-biomass conversion factors for aquatic hyphomycetes. Applied and Environmental Microbiology 59(2), 502-507.

Gilbertson RL. 1981 - North American wood-rotting fungi that cause brown rots. Mycotaxon 12(2), 372-416.

Griffith GW, Shaw DS. 1998 - Polymorphisms in Phytophthora infestans: four mitochondrial haplotypes are detected after PCR amplification of DNA from pure cultures or from host lesions. Applied and Environmental Microbiology 64(10), 4007-4014.

Hedger JN. 1982 - Degradation of lignin by fungi. In Primrose SB, Wardlaw AC. Sourcebook of Experiments for the Teaching of Microbiology. - Academic Press, London.

Hibbett DS, Donoghue MJ. 2001 - Analysis of character correlations among wood decay mechanisms, mating systems, and substrate ranges in homobasidiomycetes. Systematic Biology 50(2), 215-242.

Jarosz-Wilkolazka A, Kochmanska-Rdest J, Malarczanyk E, Wardas W, Leonowicz A. 2002 Fungi and their ability to decolourize azo and anthraquinonic dyes. Enzyme and Microbial Technology 30(4), 566-572.

Jellison J, Connolly J, Goodell B, Doyle B, Illman B, Fekete F, Ostrofsky A. 1997 - The role of cations in the biodegradation of wood by the brown rot fungi. International Biodeterioration \& Biodegradation 39(2), 165-179.

Kersten P, Cullen D. 2014 - Copper radical oxidases and related extracellular oxidoreductases of wood-decay Agaricomycetes. Fungal Genetics and Biology 72, 124-130.

Larsson K-H, Larsson E, Koljalg U. 2004 - High phylogenetic diversity among corticioid homobasidiomycetes. Mycological Research 108(09), 983-1002.

Levin L, Forchiassin F, Viale A. 2005 - Ligninolytic enzyme production and dye decolorization by Trametes trogii: application of the Plackett-Burman experimental design to evaluate nutritional requirements. Process Biochemistry 40(3), 1381-1387.

Linde D, Ruiz-Duenas FJ, Fernandez-Fueyo E, Guallar V, Hammel KE, Pogni R, Martinez AT. 2015 - Basidiomycete DyPs: Genomic diversity, structural,functional aspects, reaction mechanism and environmental significance. Archives of Biochemistry and Biophysics 574, 66-74.

Lindner DL, Banik MT. 2008 - Molecular phylogeny of Laetiporus and other brown rot polypore genera in North America. Mycologia 100(3), 417-430.

Lombard FF, Gilbertson RL. 1965 - Studies on some western Porias with negative or weak oxidase reactions. Mycologia 57(1), 43-76.

Manter D, Kelsey R, Stone J. 2001 - Quantification of Phaeocryptopus gaeumannii colonization in Douglas-Fir needles by ergosterol analysis. Forest Pathology 31, 229-240.

Ohm RA, Riley R, Salamov A, Min B, Choi I-G, Grigoriev IV. 2014 - Genomics of wooddegrading fungi. Fungal Genetics and Biology 72, 82-90. 
Ostrofsky A, Jellison J, Smith KT, Shortle WC. 1997 - Changes in cation concentrations in red spruce wood decayed by brown rot and white rot fungi. Canadian Journal of Forest Research 27(4), 567-571.

Rajchenberg M, Robledo G. 2013 - Pathogenic polypores in Argentina. Forest Pathology 43(3), 171-184.

Riley R, Salamov AA, Brown DW, Nagy LG, Floudas D, Held BW, Levasseur A, Lombard V, Morin E, Otillar R. 2014 - Extensive sampling of basidiomycete genomes demonstrates inadequacy of the white-rot/brown-rot paradigm for wood decay fungi. Proceedings of the National Academy of Sciences 111(27), 9923-9928.

Ruiz-Duenas FJ, Lundell T, Floudas D, Nagy LG, Barrasa JM, Hibbett DS, Martinez AT. 2013 Lignin-degrading peroxidases in Polyporales: an evolutionary survey based on 10 sequenced genomes. Mycologia 105(6), 1428-1444.

Ruiz-Duenas FJ, Martinez AT. 2009 - Microbial degradation of lignin: how a bulky recalcitrant polymer is efficiently recycled in nature and how we can take advantage of this. Microbial Biotechnology 2(2), 164-177.

Salvachua D, Prieto A, Martinez AT, Martinez MJ. 2013 - Characterization of a novel dyedecolorizing peroxidase (DyP)-type enzyme from Irpex lacteus and its application in enzymatic hydrolysis of wheat straw. Applied and Environmental Microbiology 79(14), 4316-4324.

Schwarze F, Ferner D. 2003 - Ganoderma on trees-differentiation of species and studies of invasiveness. Arboricultural Journal 27(1), 59-77.

Shi J, Sharma-Shivappa RR, Chinn M, Howell N. 2009 - Effect of microbial pretreatment on enzymatic hydrolysis and fermentation of cotton stalks for ethanol production. Biomass and Bioenergy 33(1), 88-96.

Smith WH. 2012 - Tree pathology: a short introduction. Elsevier.

Stalpers JA. 1978 - Identification of wood-inhabiting fungi in pure culture. Studies in Mycology(16), 248 pp.

Steffen KT, Hofrichter M, Hatakka A. 2002 - Purification and characterization of manganese peroxidases from the litter-decomposing basidiomycetes Agrocybe praecox and Stropharia coronilla. Enzyme and Microbial Technology 30(4), 550-555.

Sugano Y. 2009 - DyP-type peroxidases comprise a novel heme peroxidase family. Cellular and Molecular Life Sciences 66(8), 1387-1403.

Urzua U, Kersten PJ, Vicuna R. 1998 - Manganese peroxidase-dependent oxidation of glyoxylic and oxalic acids synthesized by Ceriporiopsis subvermispora produces extracellular hydrogen peroxide. Applied and Environmental Microbiology 64(1), 68-73.

Yoshida T, Sugano Y. 2015 - A structural and functional perspective of DyP-type peroxidase family. Archives of Biochemistry and Biophysics 574, 49-55.

Zmitrovich I, Malysheva V. 2014 - Studies on Oxyporus. I. Segregation of Emmia and general topology of phylogenetic tree. Mycology and Phytopathology 48, 161-171. 